\title{
Synthesis of copper and copper oxide nanomaterials by electrical discharges in water with various electrical conductivities
}

Cite as: J. Appl. Phys. 127, 023302 (2020); https://doi.org/10.1063/1.5129647

Submitted: 01 October 2019 . Accepted: 22 December 2019 . Published Online: 09 January 2020

Xavier Glad, Jacopo Profili (D), Min Suk Cha (D), and Ahmad Hamdan (iD)

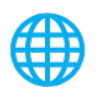

\section{ARTICLES YOU MAY BE INTERESTED IN}

Dielectric nanotomography based on electrostatic force microscopy: A numerical analysis Journal of Applied Physics 127, 024301 (2020); https://doi.org/10.1063/1.5122984

Nano-second temporal particle behavior in high-power impulse magnetron sputtering discharge in a cylindrical cathode

Journal of Applied Physics 127, 023301 (2020); https://doi.org/10.1063/1.5127565

Understanding and optimizing EBIC pn-junction characterization from modeling insights Journal of Applied Physics 127, 024502 (2020); https://doi.org/10.1063/1.5139894

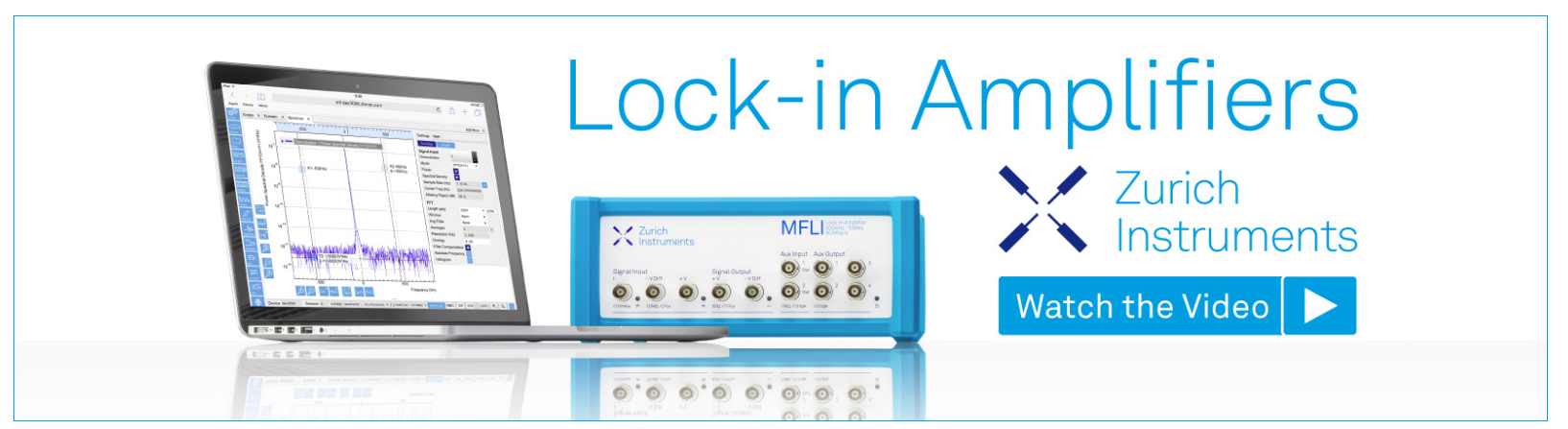




\title{
Synthesis of copper and copper oxide nanomaterials by electrical discharges in water with various electrical conductivities
}

Cite as: J. Appl. Phys. 127, 023302 (2020); doi: 10.1063/1.5129647

Submitted: 1 October 2019 - Accepted: 22 December 2019 .

Published Online: 9 January 2020

Xavier Glad, ${ }^{7}$ Jacopo Profili, $^{7}$ (D) Min Suk Cha, ${ }^{2}$ (D) and Ahmad Hamdan ${ }^{1, a) ~(D) ~}$

\begin{abstract}
AFFILIATIONS
${ }^{7}$ Groupe de physique des plasmas, Département de Physique, Université de Montréal, C.P. 6128, Succ. Centre-ville, Montréal, Québec H3C 3J7, Canada

${ }^{2}$ Physical Science and Engineering Division (PSE), Clean Combustion Research Center (CCRC), King Abdullah University of Science and Technology (KAUST), Thuwal 23955, Saudi Arabia
\end{abstract}

${ }^{a)}$ Author to whom correspondence should be addressed: ahmad.hamdan@umontreal.ca

\begin{abstract}
In the present study, Cu-based nanomaterials are synthesized by initiating spark discharges between two copper electrodes immersed in de-ionized water. The electrical conductivity of water is varied by adding $\mathrm{HCl}$ at very low concentrations. The discharge and water properties are determined by measuring the current-voltage waveforms and monitoring water acidity and conductivity, respectively. Scanning electron and transmission electron microscopy analyses of the produced nanoparticles show that increasing water conductivity, by adding $\mathrm{HCl}$, promotes the synthesis of $\mathrm{Cu}$-based nanomaterials. Depending on the initial water conductivity, various nanostructures are observed, including nanoflakes of cuprite $\left(\mathrm{Cu}_{2} \mathrm{O}\right)$, dendrites with high $\mathrm{Cu}$ content, and unordered micrometric aggregates with a mixed $\mathrm{Cu} / \mathrm{Cu}_{2} \mathrm{O}$ content. The initial water conductivity also affects the chemical structure, mainly the relative $\mathrm{Cu} / \mathrm{Cu}_{2} \mathrm{O}$ crystalline content.
\end{abstract}

Published under license by AIP Publishing. https://doi.org/10.1063/1.5129647

\section{INTRODUCTION}

Electrical discharge in and in contact with liquids is a newly developed field of research that shows great potential in a variety of applications, especially liquid and material processing. ${ }^{1}$ In fact, in-liquid discharges were recently presented as a revolutionary new route for the synthesis of nanomaterials. ${ }^{2}$ Compared to other techniques of synthesis, such as chemical vapor deposition, physical vapor deposition, and laser ablation, plasmas in or in contact with liquids are particularly interesting due to the simplicity of their experimental design. ${ }^{3}$ Furthermore, plasmas sustained in liquid medium exhibit unique properties, such as high electron density $\left(10^{17}-10^{18} \mathrm{~cm}^{-3}\right)^{4}$ and high pressure (1-100 bars), ${ }^{5}$ that promote reactivity, thereby facilitating the synthesis of materials. Several studies have demonstrated that in-liquid discharges efficiently produce nanomaterials with new crystalline phases or advanced complex nanocomposites. ${ }^{4,5}$

The synthesis of nanomaterials by electrical discharges in liquid was first reported by Sano et al. ${ }^{6}$ who used two graphite electrodes immersed in water to produce carbon nano-onions. Since then, a myriad of nanomaterials has been synthesized using the same procedure, just by varying the chemical nature of the electrodes. For example, $\mathrm{TiO}_{2}, \mathrm{Au}$, and $\mathrm{Ag}$ nanoparticles were successfully generated using $\mathrm{Ti}, \mathrm{Au}$, and $\mathrm{Ag}$ electrodes, respectively. ${ }^{7,8}$ Recently, Park et al. ${ }^{9}$ synthesized carbon-coated $\mathrm{TiO}_{2}$ nanoparticles using graphite electrodes immersed in tap water containing $\mathrm{TiO}_{2}$ nanoparticles. To expand the range of nanomaterials produced, attempts have been made to create electrical discharges in liquid hydrocarbons. For instance, Hamdan et al. ${ }^{10}$ showed that discharges between Pt electrodes immersed in n-heptane result in the generation of Pt nanoparticles (a few nanometers in diameter) embedded in a carbon matrix. This strategy limits the surface oxidation of the generated metal and metal-alloy nanomaterials, which is a problem that is commonly observed when synthesizing these species in aqueous solutions. Despite the numerous advantages of using nonoxidizing liquids, the fundamentals and mechanisms of nanomaterial synthesis in water are poorly understood and need to be investigated further. This is especially important, considering 
that water is highly abundant and environmentally friendly. On the other hand, considering that the oxides of $\mathrm{Cu}$, such as cuprite $\left(\mathrm{Cu}_{2} \mathrm{O}\right)$, tenorite $(\mathrm{CuO})$, and paramelaconite $\left(\mathrm{Cu}_{4} \mathrm{O}_{3}\right)$, are well characterized, ${ }^{11-14}$ copper constitutes a suitable metal for the analysis of nanomaterial oxidation in aqueous solutions.

In this paper, we study the influence of water's electrical conductivity on the synthesis of $\mathrm{Cu}$-based nanoparticles by pulsed spark discharges between two $\mathrm{Cu}$ electrodes immersed in water. The electrical conductivity of water is adjusted by adding $\mathrm{HCl}$ (at a very low concentration) in de-ionized water. The synthesized nanomaterials are collected and characterized using various techniques, such as scanning electron microscopy (SEM) and transmission electron microscopy (TEM).

\section{MATERIALS AND METHODS}

\section{A. Experimental setup and protocol}

As shown in Fig. 1, the experimental setup employed in this study consists of a quartz cylinder (inner diameter $=5 \mathrm{~cm}$ ) mounted on a Teflon base. Two cylindrical Cu electrodes (purity of $99.95 \%$, diameter of $2 \mathrm{~mm}$ ), provided by Goodfellow Cambridge Ltd, were fixed in the quartz cylinder above each other. The upper $\mathrm{Cu}$ electrode (anode) is movable and has a polished needlelike tip with an apex angle of about $35^{\circ}$, whereas the lower electrode is grounded and has a flat tip. Electrical pulses were produced using a high-voltage generator (Cober Electronics Inc., model 606) connected to the anode. A resistor $(300 \Omega)$ was placed in the electrical circuit between the generator and the anode to prevent arc transition. The electrical characteristics, voltage (V) and current (I), of the discharge were measured using a high-voltage probe (model P6015a from Tektronix) and a wideband terminated current transformer (model 13w5000 from Lilo, LTD), respectively. The I-V waveforms were recorded throughout the experiment using a Tektronix DPO 5204B oscilloscope.

The spark discharge was maintained by applying a pulsed voltage at a frequency of $13 \mathrm{~Hz}$, an amplitude of $4 \mathrm{kV}$, and a pulse width of $\sim 2 \mu \mathrm{s}$. To induce the breakdown, the interelectrode gap was slowly reduced from a couple of millimeters at $t=0$ to $\sim 50 \mu \mathrm{m}$

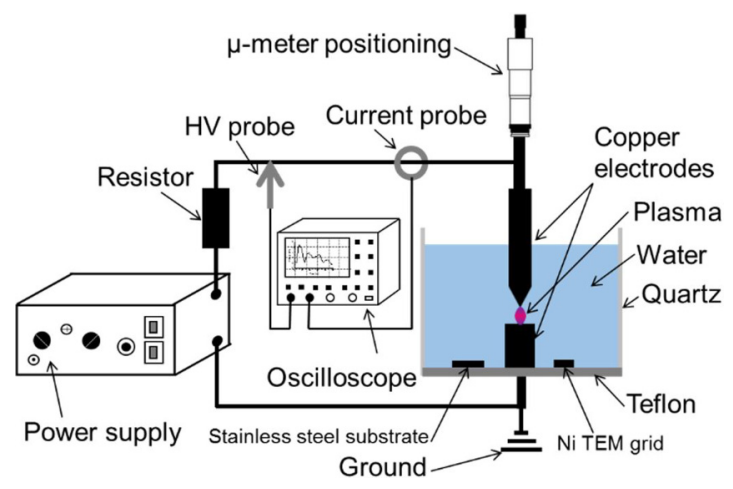

FIG. 1. Scheme of the experimental setup used to create spark discharges in water between two copper electrodes.
TABLE I. Aqueous solution conductivities and the corresponding $\mathrm{HCl}$ concentrations.

\begin{tabular}{ccccccc}
\hline \hline$\sigma\left(\mu \mathrm{S} \mathrm{cm}^{-1}\right)$ & 2 & 4 & 8 & 16 & 32 & 64 \\
\hline$[\mathrm{HCl}](\mathrm{M})$ & 0 & $5 \times 10^{-8}$ & $10 \times 10^{-8}$ & $20 \times 10^{-8}$ & $40 \times 10^{-8}$ & $80 \times 10^{-8}$ \\
\hline \hline
\end{tabular}

after applying the high voltage. Knowing that the erosion of electrodes during discharge slightly increases the interelectrode distance, ${ }^{15}$ the gap was continuously adjusted using a micrometer positioning system. Because the breakdown voltage is highly sensitive to the gap distance (among other parameters, such as the electrodes' geometry), we considered it as a reference, and the gap is continuously adjusted to ensure that the breakdown occurs at the same voltage. Therefore, because the electrical characteristics (I-V) of the discharge did not significantly change during the experiment, the deposited energy measured from I-V remained at 6-7 mJ (more information about the electrical characteristics is provided in Fig. $\mathrm{S} 1$ in the supplementary material).

Before each experiment, every part of the apparatus was thoroughly cleaned using acetone, methanol, and de-ionized water. The clean quartz cell was then filled with $50 \mathrm{ml}$ of water whose conductivity and acidity $(\mathrm{pH})$ were measured before and after each run using a Cole-Palmer Instrument electrical conductivity meter and a VWR SB20 pH meter, respectively. To assess the effect of water electrical conductivity $(\sigma)$ on the efficiency of nanoparticle, waters with $\sigma$ values of $2,4,8,16,32$, and $64 \mu \mathrm{S} \mathrm{cm}^{-1}$ were tested. The initial electrical conductivity of water was adjusted by adding various amounts of highly diluted $\mathrm{HCl}$ solution to de-ionized water $\left(\sigma=2 \mu \mathrm{S} \mathrm{cm}^{-1}\right)$. For example, the $16 \mu \mathrm{S} \mathrm{cm}^{-1}$ water sample was prepared by dissolving 1 microdrop $(1 / 60 \mathrm{ml})$ of $12 \%$ (mass concentration) $\mathrm{HCl}$ in $300 \mathrm{ml}$ of de-ionized water. The resulting solution has an $\mathrm{HCl}$ concentration of about $6.67 \times 10^{-4} \%$ by mass, which is equivalent to $20 \times 10^{-8} \mathrm{M}$. The $\mathrm{HCl}$ concentrations of all prepared water samples are listed in Table I.

\section{B. Ex situ diagnostics}

The nanoparticles collected on the SS substrate were observed by an optical microscope (OMAX M83MPTR) and then analyzed by an SEM (JEOL JSM6700F) in secondary emission mode (at $3 \mathrm{kV}$ ) or by energy dispersive X-ray spectroscopy (EDS, at $5 \mathrm{kV})$. Meanwhile, the nanoparticles collected on the $\mathrm{Ni}$ grid were analyzed by TEM (JEOL JEM-2100F) operated at $200 \mathrm{kV}$ in bright field, selected area electron diffraction (SAED), and EDS modes.

\section{RESULTS}

Observations of the solution and electrodes after plasma treatment show an increase in the liquid's opacity due to the formation of nanoparticle clouds, as well as an augmentation in the anode apex angle due to the erosion of the upper electrode (Fig. S2 in the supplementary material). Knowing that these observations are more pronounced under high conductivity conditions and that greater masses of nanomaterial are collected on the substrate/grid when $\sigma$ is higher, it is concluded that the yield of synthesized 

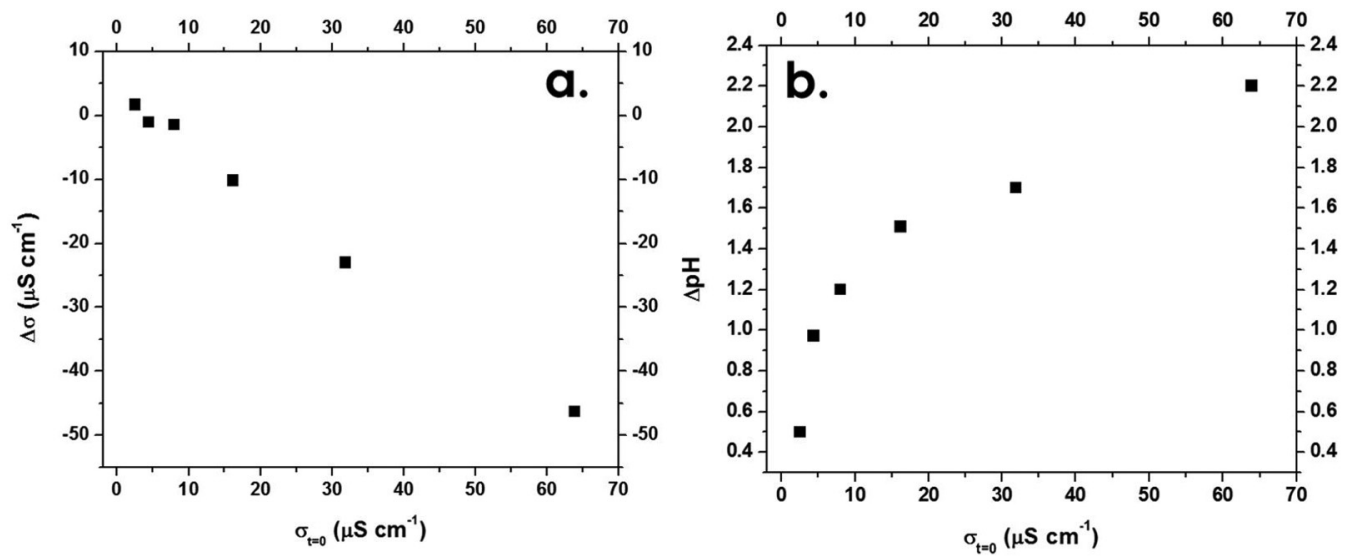

FIG. 2. Evolution of $\Delta \sigma=\left[\sigma\left(\mathrm{t}=10^{\prime}\right)-\sigma(\mathrm{t}=0)\right]$ and $\Delta \mathrm{pH}=\left[\mathrm{pH}\left(\mathrm{t}=10^{\prime}\right)-\mathrm{pH}(\mathrm{t}=0)\right]$ as a function of initial water conductivity after 10 min of discharge processing.

nanoparticles increases with increasing electrical conductivity of water. These observations agree with those reported in previous studies ${ }^{16,17}$ using similar plasma-liquid conditions.

The effect of plasma discharge on the conductivity and acidity of water was assessed. As shown in Fig. $2, \Delta \sigma=\left[\sigma\left(t=10^{\prime}\right)-\sigma(t=0)\right]$ strongly decreases with increasing initial water conductivity and nanomaterial yield, while $\Delta \mathrm{pH}$ significantly increases. This implies that the yield of $\mathrm{Cu}$-based material influences the ion density in the solution and, more likely, the $\mathrm{H}^{+}\left(\right.$or $\mathrm{H}_{3} \mathrm{O}^{+}$) concentration. The continuously changing water properties result in the modification of the synthesized nanomaterials during discharge. For the sake of clarity, all conductivities referred to hereafter are the initial values at $t=0$, although correspondences between conductivity and $\mathrm{HCl}$ concentration can be deduced from Table I.

Based on SEM and TEM analyses, three families of nanomaterials were identified in the solid samples collected after plasma treatment: (i) unordered micrometric aggregates (UMAs), (ii) nanoflakes, and (iii) dendrites. The composition of each type of material was assessed by EDS (Fig. S3 in the supplementary material), along with the geometrical, chemical, and crystalline properties. Interestingly, the analyses show no Cl-bearing species in the synthesized nanomaterial.

\section{A. SEM analysis}

The SEM images of UMAs collected from $\sigma=2,16$, and $64 \mu \mathrm{S} \mathrm{cm}^{-1}$ solutions show sizable agglomerates that are several micrometers thick and tens of micrometers large (Fig. 3). These agglomerates are composed of thousands of irregularly arranged nanoparticles whose size cannot be accurately determined using the SEM employed in this study. Indeed, objects with dimensions below $\sim 20 \mathrm{~nm}$ are not properly resolved with this microscope. Although the shape of the nanoparticles produced at low initial conductivity values cannot be precisely defined (rectangular, oval, or spherical), as $\sigma$ increases, more and more rectangular-shaped particles are produced, with lengths greater than $\sim 80 \mathrm{~nm}$ [e.g., Fig. 3(d)]. Such rectangular geometry is commonly associated with cuprite $\left(\mathrm{Cu}_{2} \mathrm{O}\right)^{11}$ and implies that the synthesized nanomaterials are made of a single crystal. The SEM images of UMAs collected from $\sigma=4,8$, and $32 \mu \mathrm{S} \mathrm{cm}^{-1}$ solutions are similar to those depicted in Fig. 3 and thus are not provided.

Typical SEM images of isolated nanoflakes are displayed in Fig. 4 for conditions of $\sigma=16$ and $64 \mu \mathrm{S} \mathrm{cm}^{-1}$. Note that nanoflakes are not observed at lower $\sigma \leq 16 \mu \mathrm{S} \cdot \mathrm{cm}^{-1}$. They show submicronic nanostructures, with diameters ranging between 20 and $200 \mathrm{~nm}$, scattered on the SS surface. The most sizable structures seem to consist of a few nanoparticles [Fig. 4(a) and the inset of Fig. 4(b)].

Dendrites are only detected at low conductivities $\left(\sigma \leq 16 \mu \mathrm{S} \mathrm{cm}^{-1}\right)$. They are a few micrometers long and are made of very small nanoparticles, as shown in Fig. 5. Compared to UMAs, dendrites are larger, not compacted, and follow a linear dendritic growth. However, their geometrical features cannot be determined exactly due to the limited resolution of the SEM. Therefore, the morphologies of the produced nanoparticles were further analyzed using TEM.

\section{B. TEM bright field imaging}

The different types of structures identified by SEM were further investigated using TEM analyses. As previously observed in SEM, UMAs are produced under all investigated discharge conditions, and their nanoparticle sizes are generally independent of conductivity (Fig. 6), except for the seldom occurrence of rectangular-shaped particles at relatively higher $\sigma$ values [Fig. 6(b)]. Meanwhile, the nanoflakes are mostly composed of seemingly flat nanostructures joined together along a common plane (Fig. 7). Based on the acquired TEM images, the particles in dendrites are ovoidal in shape, with sizes ranging between 6 and $12 \mathrm{~nm}$ (Fig. 8). The peculiar shape of the dendrites may be attributed to their specific growth mechanism.

Additional data concerning the structure and composition of the synthesized nanoparticles, particularly oxygen content, were 

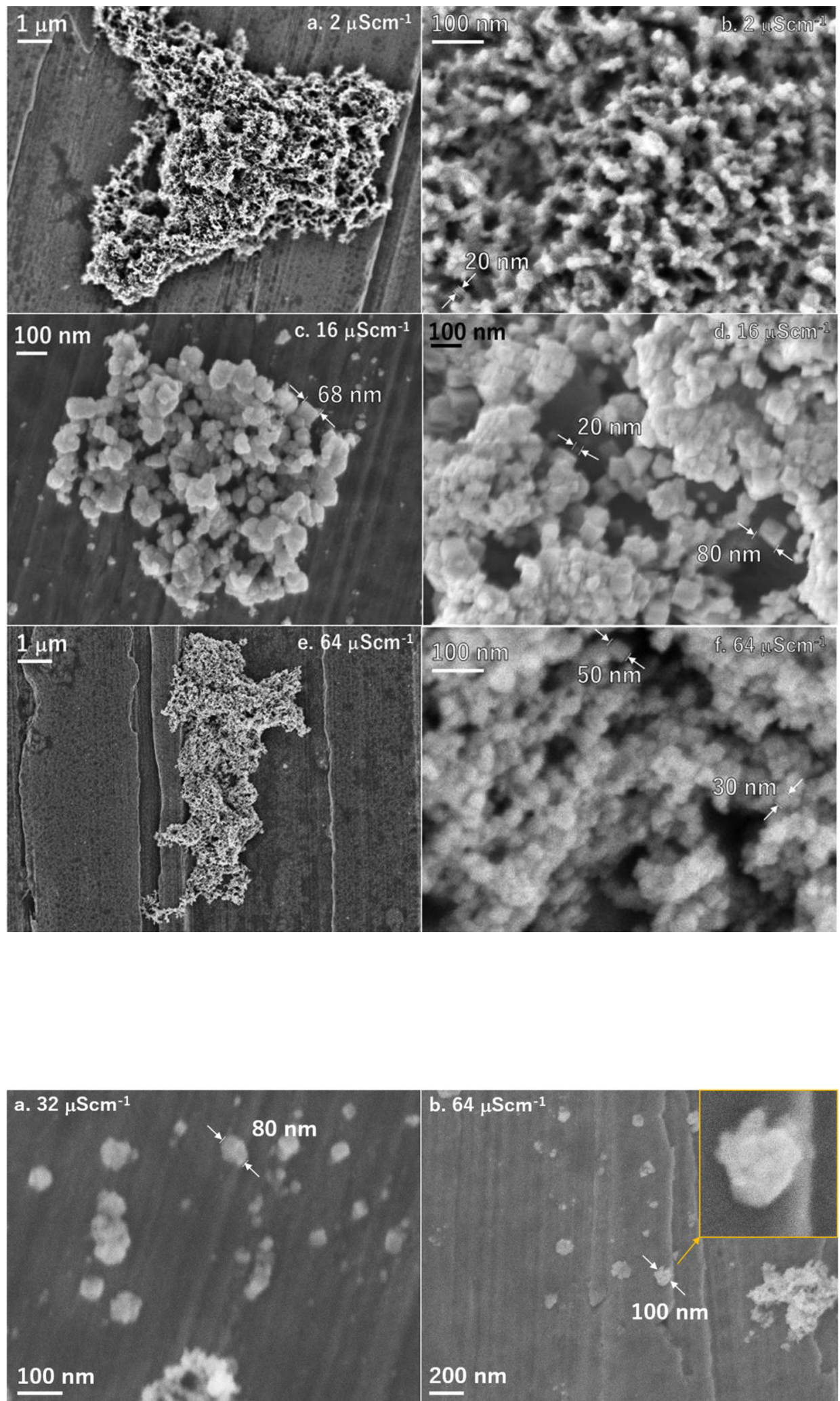

FIG. 3. SEM micrographs of UMAs collected on SS substrate for [(a) and (b)] $\sigma=2 \mu \mathrm{S} \mathrm{cm}^{-1}, \quad[(\mathrm{c})$ and (d)] $\sigma=16 \mu \mathrm{S} \mathrm{cm}^{-1}$, and [(e) and (f)] $\sigma=64 \mu \mathrm{S} \mathrm{cm}^{-1}$. Other conductivities show similar aggregates and are, thus, not displayed.
FIG. 4. SEM images of Cu-based nanoflakes collected on SS substrates. They are evenly scattered throughout the substrates and occur only at $\sigma \geq 16 \mu \mathrm{S} \mathrm{cm}^{-1}$. 


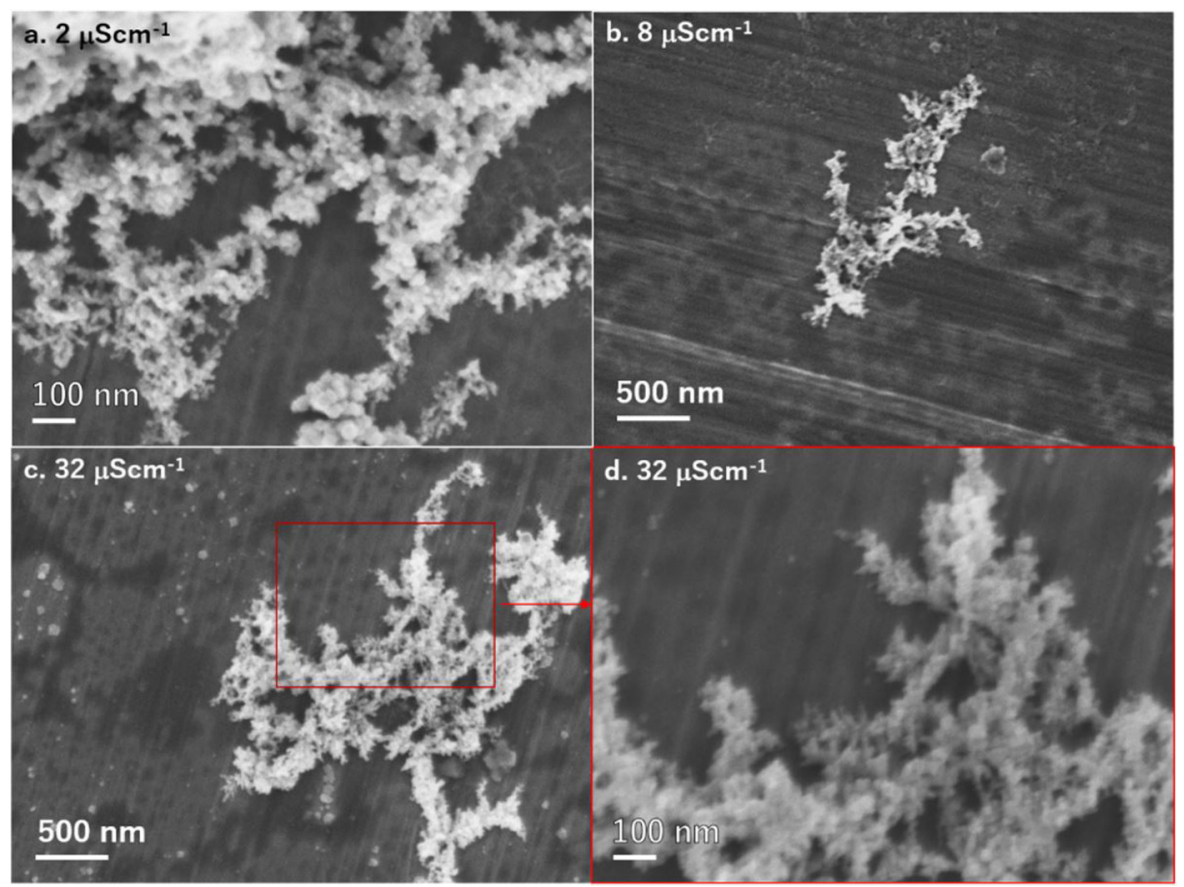

FIG. 5. SEM images of Cu-based dendrite agglomerates recorded under varying conditions of conductivity. determined using EDS, which allows for the assessment of the implicated mechanism.

\section{Electron diffraction and high-resolution imaging}

The crystallinity of the synthesized nanomaterial was assessed using SAED pattern analysis. We used the original method, as reported by He et al., ${ }^{18}$ to interpret the SAED data. This technique is based on the use of an ImageJ plugin to generate the Radial Profile Plot. ${ }^{19}$ Briefly, the plugin adds up the pixel intensities of the diffraction pattern over concentric circles of different radii, defined from the center of the diffraction pattern, and divides it by the number of pixels forming each respective circle. This method results in normalized integrated intensities that are represented in Figs. 9(b)-9(d) as peaks corresponding to every crystal plane at an interplanar distance $d_{h k l}$. The peaks are identified and deconvoluted using the Lorentzian profile, and their respective areas are compared.

The SAED data presented in Figs. 9(b)-9(d) for conditions of $\sigma=2,16$, and $64 \mu \mathrm{Scm}^{-1}$, respectively, show that the synthesized nanomaterial exhibits exclusively $\mathrm{Cu}$ and $\mathrm{Cu}_{2} \mathrm{O}$ crystalline features, especially the cuprite (110), (111), and (200) planes at interplanar distances of $3.02,2.47$, and $2.13 \AA$, respectively, and the copper (111) and (200) planes at 2.09 and $1.81 \AA$, respectively, are identified. Other copper oxides, such as tenorite $(\mathrm{CuO})$ and paramelaconite $\left(\mathrm{Cu}_{4} \mathrm{O}_{3}\right)$, were not observed.

The peak area ratio of $\mathrm{Cu}(200)$ over $\mathrm{Cu}_{2} \mathrm{O}(111)$ was selected for the qualitative analysis of the generated nanoparticles using the radial integration technique. The more intense peak of $\mathrm{Cu}(111)$ at $2.09 \AA$ could not be used for this analysis, because it overlaps with the $\mathrm{Cu}_{2} \mathrm{O}(200)$ peak at $2.13 \AA$, and thus its estimated area comprises a significant margin of error. Furthermore, the qualitative analysis of nanoparticles was performed on UMAs and dendrites only but not on nanoflakes due to the lack of statistically relevant data of crystal orientations. The obtained results show that $\mathrm{Cu}_{2} \mathrm{O}$ content increases sharply, i.e., $\mathrm{Area}[\mathrm{Cu}(200)] / \mathrm{Area}\left[\mathrm{Cu}_{2} \mathrm{O}(111)\right]$ decreases, with increasing water conductivity up to $64 \mu \mathrm{S} \mathrm{cm}^{-1}$, where $\mathrm{Cu}(200)$ completely disappears [Fig. 10(a)]. Moreover, dendritessynthesized only under low $\sigma$ conditions-exhibit higher $\mathrm{Cu}$ content than UMAs but are always mixed with cuprite.

The $d$-spacing of $(200)$ copper planes, $d_{200}(\mathrm{Cu})$, was also extracted from the diffraction patterns and was found to vary with the crystalline content of the nanoparticles. The variation of $d_{200}(\mathrm{Cu})$ is thus analyzed as a function of $\mathrm{Area}[\mathrm{Cu}(200)] /$ Area $\left[\mathrm{Cu}_{2} \mathrm{O}(111)\right]$, as shown in Fig. 10 (b). The results demonstrate that $d_{200}(\mathrm{Cu})$ decreases from its original undisturbed value of $1.81 \AA$ to a minimum value of $1.70 \AA$, as $\mathrm{Cu}_{2} \mathrm{O}$ content increases. This implies that the oxidation of $\mathrm{Cu}$ crystals includes a step where the distance between atomic planes significantly shrinks, which is consistent with previously reported results. ${ }^{20}$

The size distribution of the generated crystals was assessed using high-resolution TEM (HRTEM) imaging (Figs. 11 and 12). However, $\mathrm{Cu}$ crystals could not be observed due to the limited resolution of the employed TEM. The HRTEM images of $\mathrm{Cu}_{2} \mathrm{O}$ crystals belonging to the dendrite and UMA families are shown in Fig. 11. In dendrites, the size distribution of cuprite crystals is rather narrow and ranges from 5 to $12 \mathrm{~nm}$ [Fig. 11(a)], whereas in UMAs, the distribution is relatively wider and ranges from 6 to $20 \mathrm{~nm}$ [Figs. 11(b)-11(d)]. Note that a clear relationship between conductivity and size could not be discerned, probably due to the fact that $\sigma$ varies during the treatment, especially for the highest initial conductivity [Fig. 2(a)]. 

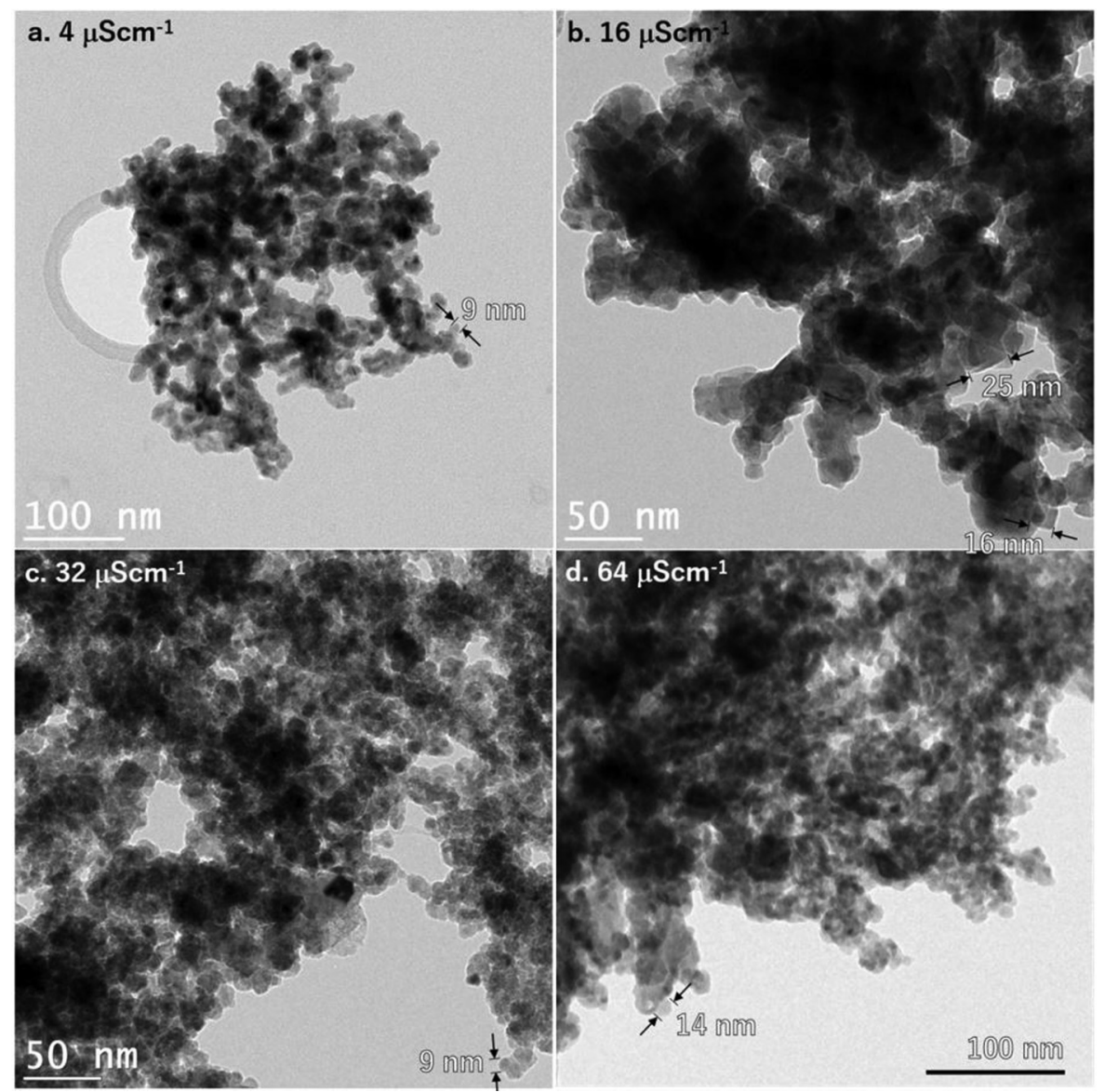

FIG. 6. TEM bright field images of UMAs produced at (a) $\sigma=4 \mu \mathrm{S} \mathrm{cm}^{-1}$, (b) $\sigma=16 \mu \mathrm{Scm}^{-1}$, (c) $\sigma=32 \mu \mathrm{S} \mathrm{cm}^{-1}$, and (d) $\sigma=64 \mu \mathrm{S} \mathrm{cm}^{-1}$.

Based on the HRTEM images shown in Fig. 12, nanoflakes are the family with the most sizable $\mathrm{Cu}_{2} \mathrm{O}$ crystals $(10-35 \mathrm{~nm})$. Moreover, each well-defined nanoparticle in the nanoflake family is comprised of a single $\mathrm{Cu}_{2} \mathrm{O}$ crystal, and the particles are joined together by what appears to be grain boundaries.

\section{Size determination of crystallites: Scherrer equation}

In addition to the size distribution assessment of cuprite crystals using HRTEM imaging, the sizes of $\mathrm{Cu}$ and $\mathrm{Cu}_{2} \mathrm{O}$ were also estimated via the commonly known Scherrer equation ${ }^{21,22}$ [Eq. (1)],
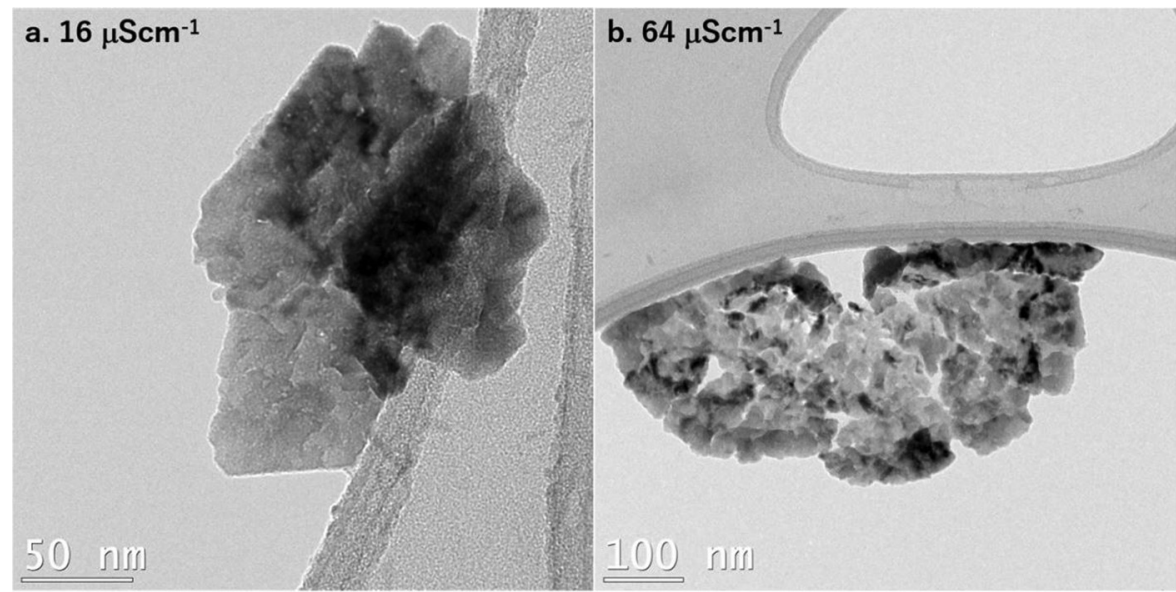

FIG. 7. TEM bright field images of nanoflakes produced under high conductivity conditions. 


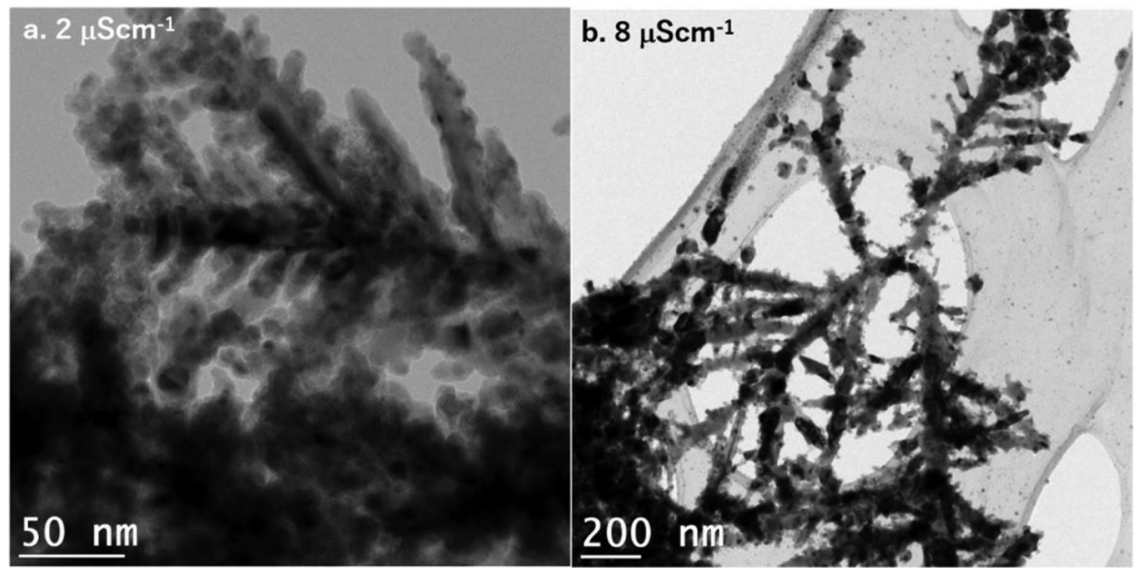

FIG. 8. TEM bright field images of dendrites. Particle sizes ranging between 6 and $12 \mathrm{~nm}$.
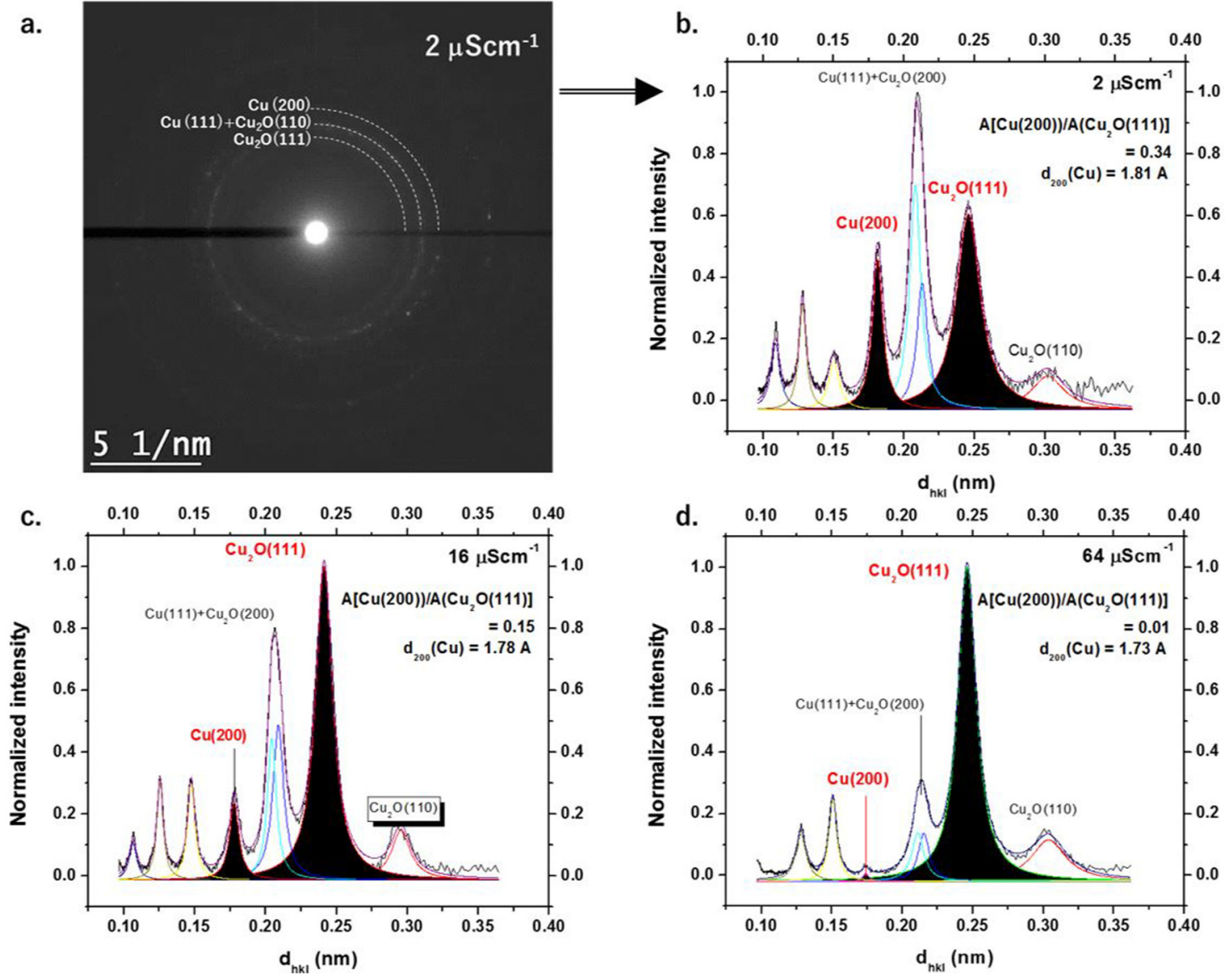

FIG. 9. TEM SAED radial profile analysis, examples for $\sigma=2 \mu \mathrm{S} \mathrm{cm}^{-1}$ [(a) leads to (b)], $\sigma=16 \mu \mathrm{S} \mathrm{cm}^{-1}$ (c), and $\sigma=64 \mu \mathrm{S} \mathrm{cm}^{-1}$ (d). Each diffraction pattern is converted into a normalized sum of $h \mathrm{kl}$ reflection intensities that is represented by a Lorentzian-fitted peak. $\mathrm{Cu}(200)(1.81 \AA)$ and $\mathrm{Cu}_{2} \mathrm{O}(111)(2.46 \AA)$ areas are extracted to assess the relative oxide content. 

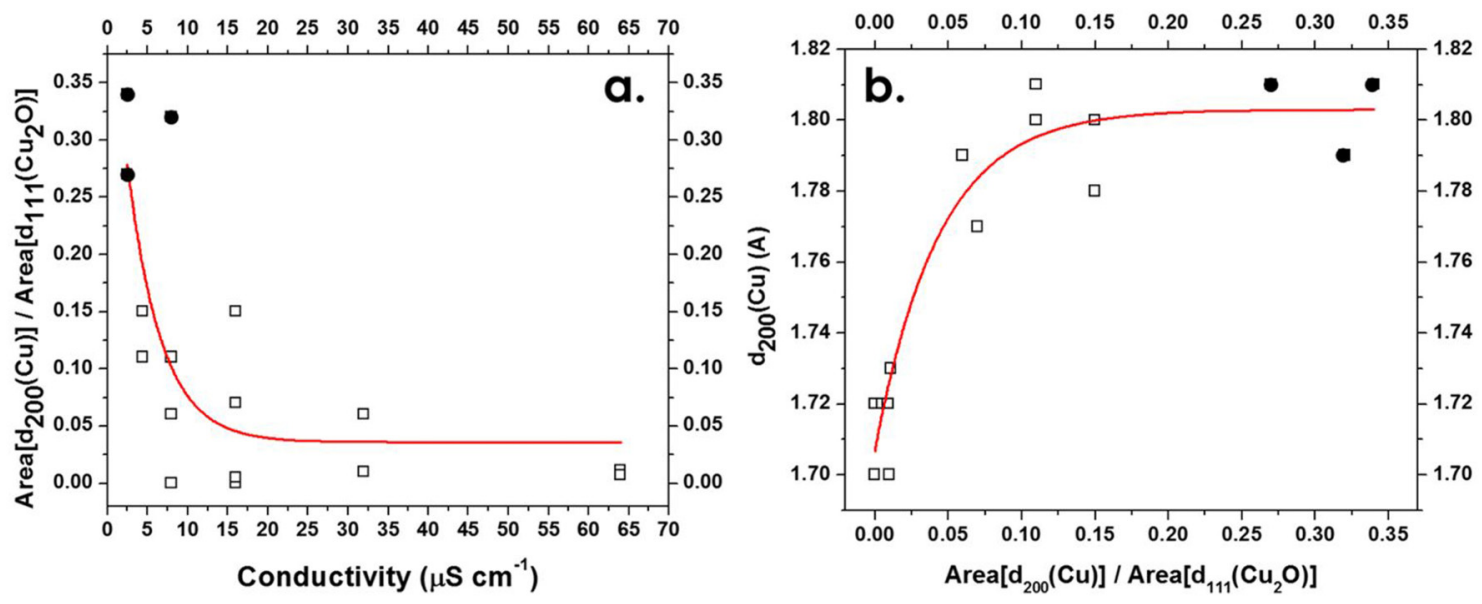

FIG. 10. Qualitative analyses of SAED radial profiles for UMAs (squares) and dendrites (circles).

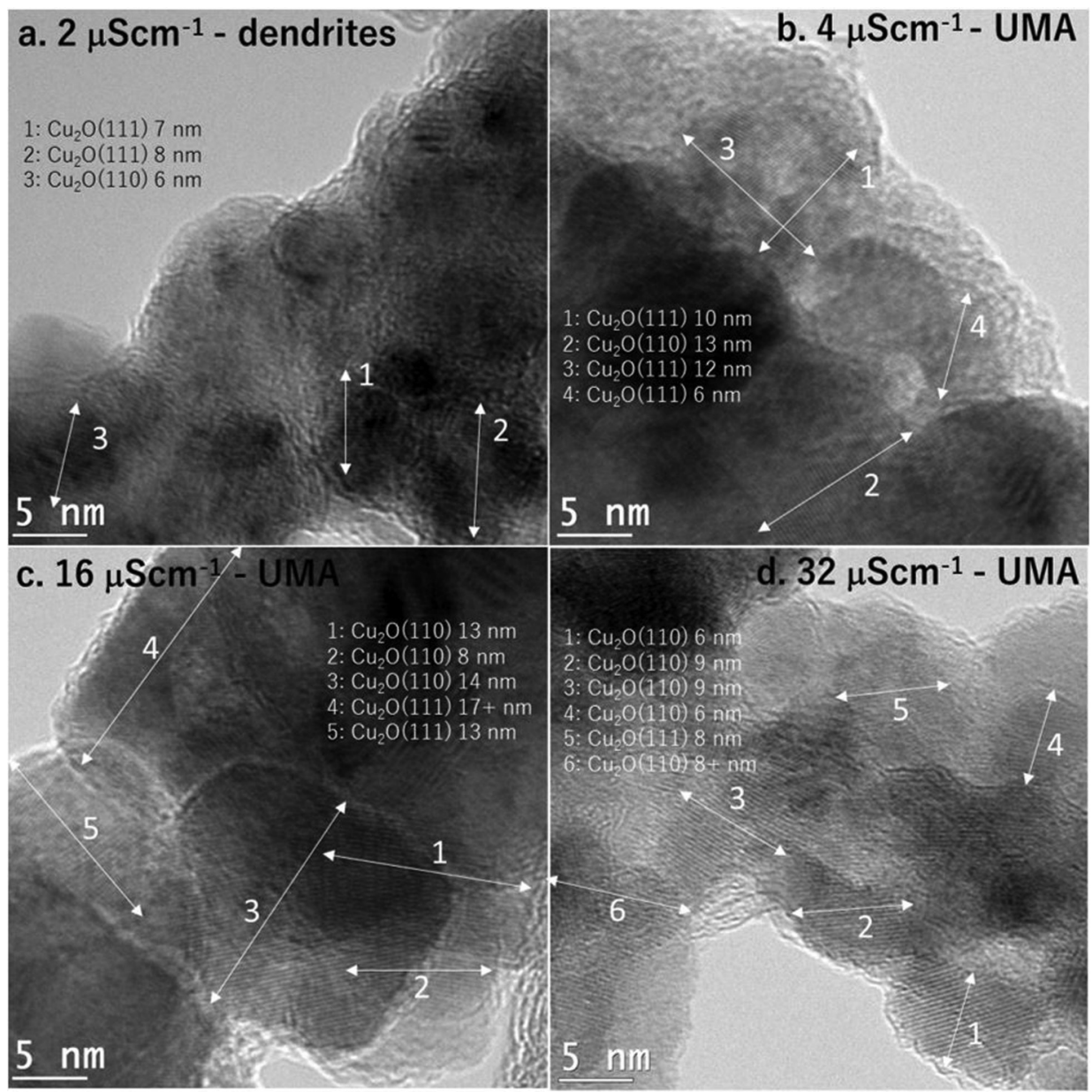

FIG. 11. HRTEM images of $\mathrm{Cu}_{2} \mathrm{O}$ crystals found in dendrites $\left(2 \mu \mathrm{S} \mathrm{cm}^{-1}\right)$ and UMAs $\left(4,16\right.$, and $\left.32 \mu \mathrm{S} \mathrm{cm}^{-1}\right)$. 


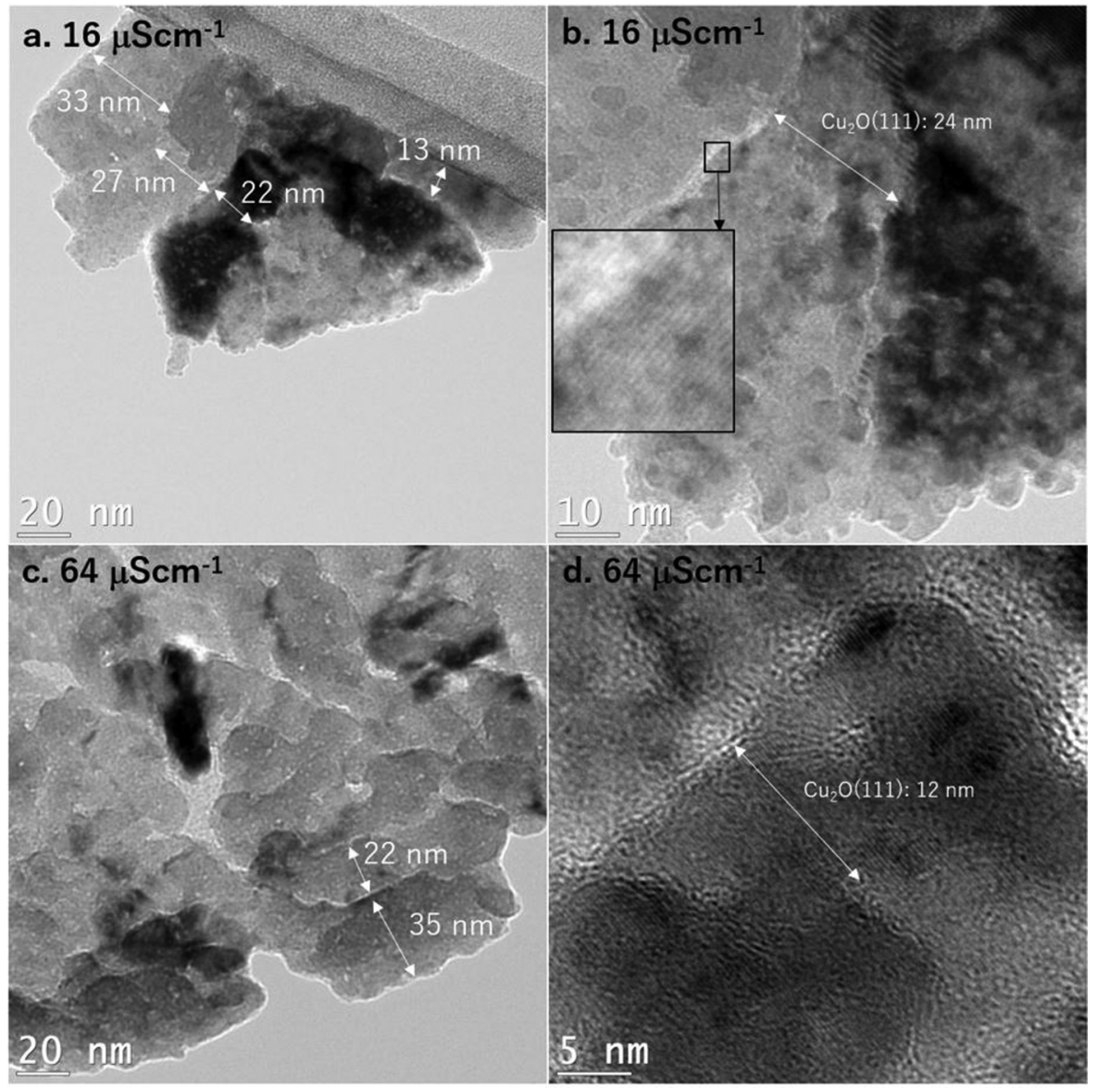

FIG. 12. TEM and HRTEM images of nanoflakes synthesized under conditions of $\sigma=16$ and $64 \mu \mathrm{S} \mathrm{cm}^{-1}$. using the data supplied by electron diffraction measurements ${ }^{23}$

$$
D=\frac{0.9 \lambda}{\beta_{h k l} \cos \theta_{h k l}},
$$

where $D(\AA)$ is the crystal size, 0.9 is the Scherrer constant, $\lambda$ (in $\AA$ ) is the incident electron wavelength (following Ref. 24), $\theta_{h k l}$ is the Bragg angle, and $\beta_{h k l}$ is the full width at half maximum of the $h k l$ reflection intensity peak (in rad).

The Scherrer method may only be applied on single and well-defined peaks of the SAED pattern. It is typically used for structures composed of a few crystallites, such as nanoflakes or small selected areas of UMAs and dendrites, which renders it a tedious method that does not lead to statistically relevant results. However, it is very useful in highlighting size trends.

To ensure that the applicability of the Scherrer law for polycrystalline dendrites and UMAs, the sizes of single crystal $\mathrm{Cu}_{2} \mathrm{O}$ nanoflakes determined using Eq. (1) were compared to those extracted from HRTEM and are found very close. The Scherrer-calculated crystal sizes for $\mathrm{Cu}_{2} \mathrm{O}$ (red) and $\mathrm{Cu}$ (black) in the nanoflake (purple), dendrite (blue), and UMA (green) families are presented in Fig. 13. The results show that, at low water conductivity

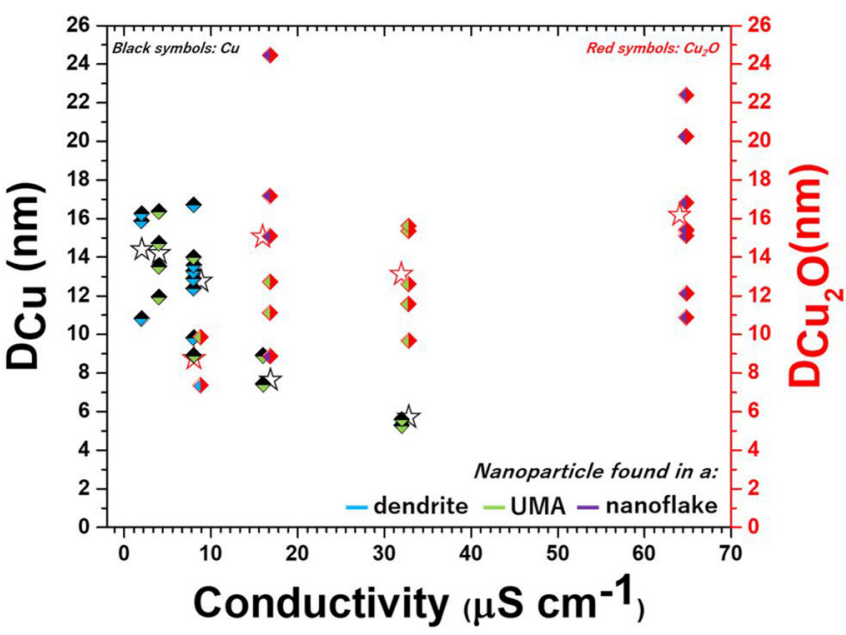

FIG. 13. Scherrer estimation of $\mathrm{Cu}\left(\mathrm{D}_{\mathrm{Cu}}\right.$, black) and $\mathrm{Cu}_{2} \mathrm{O}\left(\mathrm{D}_{\mathrm{Cu}_{2} \mathrm{O}}\right.$, red) crystal sizes synthesized under various water conductivities. Open star symbols (slightly shifted for clarity) indicate the mean values with the corresponding color scheme. 
$\left(\sigma \leq 4 \mu \mathrm{S} \mathrm{cm}^{-1}\right)$, no isolated $\mathrm{Cu}_{2} \mathrm{O}$ peaks are detected, whereas at high conductivity $\left(\sigma=64 \mu \mathrm{S} \mathrm{cm}^{-1}\right)$, no $\mathrm{Cu}$ peaks are observed. This confirms the evolution of the oxidation state with the modification of water conductivity. The results also demonstrate that $\mathrm{Cu}$ crystal size decreases with increasing water conductivity, especially in UMAs. However, no clear relation could be identified between $\mathrm{Cu}_{2} \mathrm{O}$ size and conductivity within the UMA family.

\section{DISCUSSION}

The effect of water conductivity on the crystallinity of $\mathrm{Cu}$-based nanomaterials produced by discharges in water was assessed. The obtained results indicate that increasing conductivity enhances the yield of synthesized nanomaterial, which ultimately leads to an increase in $\mathrm{pH}$ (loss of $\mathrm{H}^{+} / \mathrm{H}_{3} \mathrm{O}^{+}$species and/or increase in $\mathrm{OH}^{-}$density) and a decrease in conductivity (mainly loss of $\mathrm{H}^{+} / \mathrm{H}_{3} \mathrm{O}^{+}, \mathrm{Cl}^{-}$, and other charged species) of the plasma-treated solution. However, the average energy of the discharge $(\sim 6-7 \mathrm{~mJ})$ was found to be independent of water conductivity.

Three major families of nanostructures were identified in the collected solid material: unordered micrometric agglomerates (UMAs), nanoflakes, and dendrites. The former consists of $\mathrm{Cu}$ and $\mathrm{Cu}_{2} \mathrm{O}$ nanoparticles and are detected at all investigated conductivity conditions $\left(2,4,8,16,32\right.$, and $\left.64 \mu \mathrm{S} \mathrm{cm}^{-1}\right)$. Note that with increasing $\sigma$, a rise in $\mathrm{Cu}_{2} \mathrm{O}$ content and a decrease in $\mathrm{Cu}(200) d$-spacing are observed. The nanoflakes, on the other hand, could only be detected at $\sigma \geq 16 \mu \mathrm{Scm}^{-1}$ and are made out of larger $\mathrm{Cu}_{2} \mathrm{O}$ crystals joined together in a single $2 \mathrm{D}$ plane by grain boundaries. Finally, the dendrites are predominantly found at low $\sigma$ and are primarily comprised of $\mathrm{Cu}$.

The size of the copper crystals decreases with increasing conductivity due to the enhanced oxidation of pure $\mathrm{Cu}$ nanoparticles. Meanwhile, since the $\mathrm{Cu}_{2} \mathrm{O}$ crystals may not reach a size significantly greater than the copper crystals from which they grew, their size is independent of water conductivity.

Overall, the results show that rising initial conductivity (or the addition of $\mathrm{HCl}$ ) increases the yield of $\mathrm{Cu}$-based particles and $\mathrm{Cu}_{2} \mathrm{O}$ content. Diverse changes in water conductivity $(\Delta \sigma)$ and acidity $(\Delta \mathrm{pH})$ are observed throughout each experiment. When using water of low initial conductivity, an increase in conductivity is induced by an electrolysislike process. Meanwhile, when starting with a relatively high conductivity value, $\Delta \sigma$ decreases. This observation is most likely linked with the greater yield of $\mathrm{Cu}$-bearing nanoobjects at higher initial water conductivity, and it may be explained by the collection of charged species at the surface of the synthesized nanomaterials in the liquid phase. Such behavior is commonly detected in conventional plasma processes (silane, ${ }^{25}$ acetylene, ${ }^{26}$ preformed nanoparticles in nitrogen, ${ }^{27}$ etc.) where particles are known to collect ions and radicals.

In this study, we use $\mathrm{HCl}$ to vary the initial concentration of water. Therefore, the increase in $\mathrm{Cu}$-based nanoparticle yield can be explained by the contribution of $\mathrm{Cl}$-based radicals via chemical erosion/corrosion, in addition to the physical erosion (sputtering and evaporation). Since chemical erosion is well known to be enhanced at local defects, such as grain boundaries, this phenomenon is assumed to be the source of the $\mathrm{Cu}_{2} \mathrm{O}$ nanoflakes observed at high conductivities. ${ }^{28}$ Moreover, the presence of $\mathrm{HCl}$ can also be used to explain the variations in $\mathrm{Cu}_{2} \mathrm{O}$ content between the different structure families. Even at very low concentrations, $\mathrm{HCl}$ may induce the formation of a $\mathrm{Cu}_{2} \mathrm{O}$ film on the surface of the electrodes. $^{29}$ In the context of copper corrosion in chloride solutions, the occurred chemical reactions are summarized in Ref. 29 (and references therein). In fact, the oxidation starts since the copper electrode is immersed in an oxygenated aqueous solution, and it rapidly corrodes to form compact and adherent films of cuprous oxide,

$$
2 \mathrm{Cu}+\mathrm{H}_{2} \mathrm{O} \rightarrow \mathrm{Cu}_{2} \mathrm{O}(\text { film })+2 \mathrm{H}^{+}+2 \mathrm{e} .
$$

At the anode and for the concentration of chloride solution $<10^{-4} \mathrm{M}$ (which is the case here), the following reactions $[(\mathrm{R} 2)$ and $(\mathrm{R} 3)]$ are reported:

$$
\begin{gathered}
\mathrm{Cu} \rightarrow \mathrm{Cu}^{+}+\mathrm{e}, \\
\mathrm{Cu}^{+}+\mathrm{Cl}^{-} \rightarrow \mathrm{CuCl} .
\end{gathered}
$$

Then, copper oxide is obtained via (R4) and (R5),

$$
\begin{gathered}
2 \mathrm{CuCl}+\mathrm{H}_{2} \mathrm{O} \rightarrow \mathrm{Cu}_{2} \mathrm{O}+2 \mathrm{H}^{+}+2 \mathrm{Cl}^{-}, \\
2 \mathrm{CuCl}+2 \mathrm{OH}^{-} \rightarrow \mathrm{Cu}_{2} \mathrm{O}+\mathrm{H}_{2} \mathrm{O}+2 \mathrm{Cl}^{-} .
\end{gathered}
$$

Although the reported reactions (R1)-(R5) are of interest in the context of copper corrosion, the plasma may also contribute significantly. Indeed, as the discharges are produced in water, highly oxidative species $\left(\mathrm{O}, \mathrm{OH}, \mathrm{H}_{2} \mathrm{O}_{2}\right.$, etc.) are produced. Simultaneously, $\mathrm{Cu}$ atoms are ejected from the electrode surface, and reactions can happen between all these species in the plasma volume, where the conditions of pressure and temperature are not well known. In such a complex highly reactive medium, identification of the involved mechanisms is not straightforward, but only qualitative description can be advanced by comparing the various investigated conditions. For example, the role of plasma species will be dominant at lower $\sigma$, but at higher conductivity, the role of Cl-based species is to be considered.

Once the discharge starts, the film is eliminated, e.g., by shock waves, leading to the formation of nanoflakes. Note that the absence of $\mathrm{Cl}$ species in the synthesized nanomaterials signifies that the $\mathrm{HCl}$ concentration is not high enough to lead to a thick $\mathrm{CuCl}$ film on the surface. ${ }^{29}$ Also, at low initial conductivity (conditions with the lowest $\mathrm{HCl}$ concentration), the $\mathrm{Cu}$ content in the synthesized nanoparticles is relatively high due to inefficient surface oxidation and chemical erosion of the electrodes. This is further supported by the fact that flakes are not synthesized at low initial conductivity. Note that $\mathrm{Cu}_{2} \mathrm{O}$ flakes, also known as patinas, are often formed in the atmosphere ${ }^{30}$ or in marine environments ${ }^{31}$ where the presence of $\mathrm{HCl}$ is confirmed.

The atoms evaporated from the electrode surface may be assembled by the dielectrophoresis mechanism, leading to the formation of dendrites and UMAs under all investigated conductivity conditions. Differences in the final shapes of these structures may be derived from the discrepancies in the electrical properties of $\mathrm{Cu}$ (no bandgap, electrical resistivity $\sim 2.1 \mu \Omega \mathrm{cm}^{-1}$ ) and $\mathrm{Cu}_{2} \mathrm{O}$ 
(bandgap $=2.45 \mathrm{eV}$, electrical resistivity $\sim 3 \times 10^{8} \mu \Omega \mathrm{cm}^{-1}$ ). ${ }^{32}$ These discrepancies influence the charge distribution on the nanoparticles' surfaces and, thus, the assembling mechanism. The colloidal agglomeration of conductive nanoparticles under an electric field is explained by the dielectrophoresis mechanism. ${ }^{33,34}$ The high $\mathrm{Cu}$ content in dendrites, compared to UMAs and nanoflakes, is attributed to linear or fractal growth, and the gradual reduction in size of $\mathrm{Cu}$ crystals is due to $\mathrm{Cl}$-favored oxidation processes arising within the solution after synthesis. Considering that no partially oxidized particles (core rich with $\mathrm{Cu}$ and shell rich with $\mathrm{Cu}_{2} \mathrm{O}$ ) were identified, further investigations are required. Finally, the gradual reduction in conductivity throughout the experiments at high initial conductivities might explain the broad nanoparticle size distribution found in UMAs.

\section{CONCLUSION}

In this study, Cu-based nanoparticles are synthesized in de-ionized water of varying initial conductivity using pulsed spark discharges between copper electrodes. To vary the initial conductivity of water, different amounts of $\mathrm{HCl}$ were added to the solution, leading to the identification of three structures of synthesized nanomaterial: dendrites, UMAs, and nanoflakes. The high $\mathrm{Cu}$ content dendrite crystals are primarily produced under conditions of low initial conductivity. Meanwhile, the UMAs and nanoflakes are mainly composed of $\mathrm{Cu}_{2} \mathrm{O}$ nanoparticles whose yield increases with rising conductivity. The changes in water conductivity and acidity observed during an experiment may be attributed to electrolysis and to the collection of charged species by the synthesized nanoparticles.

To sum up, the presented synthesis technique is reproducible (E 6-7 $\mathrm{mJ}$ for all investigated conditions), efficient (high particle yield), and extremely inexpensive (only water and traces of $\mathrm{HCl}$ are needed). The increase in a $\mathrm{Cu}$-based nanoparticle yield can be explained by the contribution of Cl-based radicals via chemical erosion/corrosion, in addition to the physical erosion (sputtering and evaporation) of the electrode surface. By adjusting water conductivity/HCl concentration, the synthesis yield and the $\mathrm{Cu} / \mathrm{Cu}_{2} \mathrm{O}$ content of nanoparticles may be easily controlled.

\section{SUPPLEMENTARY MATERIAL}

The supplementary material is about three figures. Figure S1 shows typical electrical characteristics during a discharge as well as the deposited energy as a function of plasma processing under the various conditions of electrical conductivity. Figure S2 shows photos (acquired by an optical microscope) of the surface of the SS substrates on which the synthesized nanomaterial are collected. Figure S3 shows the EDS spectra conducted during TEM analysis on dendrites and UMA particles.

\section{ACKNOWLEDGMENTS}

This publication is based upon the work supported by the King Abdullah University of Science and Technology (KAUST) Office of Sponsored Research (OSR) under Award No. OSR-2018-CARF-1975.

\section{REFERENCES}

${ }^{1}$ C. Richmonds and R. M. Sankaran, "Plasma-liquid electrochemistry: Rapid synthesis of colloidal metal nanoparticles by microplasma reduction of aqueous cations,” Appl. Phys. Lett. 93(13), 131501 (2008).

${ }^{\mathbf{2}}$ T. Belmonte, A. Hamdan, F. Kosior, C. Noël, and G. Henrion, "Interaction of discharges with electrode surfaces in dielectric liquids: Application to nanoparticle synthesis," J. Phys. D Appl. Phys. 47(22), 224016 (2014).

${ }^{3}$ M. B. Gawande et al., "Cu and $\mathrm{Cu}$-based nanoparticles: Synthesis and applications in catalysis," Chem. Rev. 116(6), 3722-3811 (2016).

${ }^{4}$ A. Hamdan, C. Noël, J. Ghanbaja, and T. Belmonte, "Comparison of aluminium nanostructures created by discharges in various dielectric liquids," Plasma Chem. Plasma Process. 34(5), 1101-1114 (2014).

${ }^{\mathbf{5}}$ A. Hamdan, H. Kabbara, C. Noël, J. Ghanbaja, A. Redjaimia, and T. Belmonte, "Synthesis of two-dimensional lead sheets by spark discharge in liquid nitrogen," Particuology 40, 152-159 (2018).

${ }^{6}$ N. Sano, H. Wang, M. Chhowalla, I. Alexandrou, and G. A. J. Amaratunga, "Synthesis of carbon 'onions' in water," Nature 414(6863), 506-507 (2001).

${ }^{7}$ L.-C. Chen and S.-H. Pai, "In-situ measurement and control of electric discharge on submerged arc synthesis process for continuous $\mathrm{TiO}_{2}$ nanoparticle fabrication," Mater. Trans. 45(10), 3071-3078 (2004).

${ }^{8}$ L. C. Chen, D. C. Tien, N. Van Thai, and S. Ashraf, "Study of Ag and Au nanoparticles synthesized by Arc discharge in deionized water," J. Nanomater. 2010, 634757.

${ }^{9}$ H. Park, S. Yoo, and K. Kim, "Synthesis of carbon-coated $\mathrm{TiO}_{2}$ by underwater discharge with capillary carbon electrode," IEEE Trans. Plasma Sci. 47(2), 1482-1486 (2019).

${ }^{10}$ A. Hamdan, C. Noël, J. Ghanbaja, S. Migot-Choux, and T. Belmonte, "Synthesis of platinum embedded in amorphous carbon by micro-gap discharge in heptane," Mater. Chem. Phys. 142(1), 199-206 (2013).

${ }^{11} \mathrm{M}$. Heinemann, B. Eifert, and C. Heiliger, "Band structure and phase stability of the copper oxides $\mathrm{Cu}_{2} \mathrm{O}, \mathrm{CuO}$, and $\mathrm{Cu}_{4} \mathrm{O}_{3}$," Phys. Rev. B 87(11), 115111 (2013).

${ }^{12} \mathrm{R}$. Kaur and B. Pal, "Cu nanostructures of various shapes and sizes as superior catalysts for nitro-aromatic reduction and co-catalyst for $\mathrm{Cu} / \mathrm{TiO}_{2}$ photocatalysis,” Appl. Catal. A 491, 28-36 (2015).

${ }^{13}$ S. E. Allen, R. R. Walvoord, R. Padilla-Salinas, and M. C. Kozlowski, “Aerobic copper-catalyzed organic reactions," Chem. Rev. 113(8), 6234-6458 (2013).

${ }^{14}$ C. R. Iordanescu, D. Tenciu, I. D. Feraru, A. Kiss, M. Bercu, D. Savastru, R. Notonier, and C. E. A. Grigorescu, "Structure and morphology of Cu-oxides films derived from PLD processes,” Dig. J. Nanomater. Bios. 6(2), 863-868 (2011).

${ }^{15}$ A. Hamdan, C. Noel, F. Kosior, G. Henrion, and T. Belmonte, "Impacts created on various materials by micro-discharges in heptane: Influence of the dissipated charge," J. Appl. Phys. 113(4), 043301 (2013).

${ }^{16}$ Y. Hattori, S. Mukasa, H. Toyota, T. Inoue, and S. Nomura, "Synthesis of zinc and zinc oxide nanoparticles from zinc electrode using plasma in liquid," Mater. Lett. 65(2), 188-190 (2011).

17Š. Potocký, N. Saito, and O. Takai, "Needle electrode erosion in water plasma discharge," Thin Solid Films 518(3), 918-923 (2009).

${ }^{18} \mathrm{~K}$. He et al., "Visualizing non-equilibrium lithiation of spinel oxide via in situ transmission electron microscopy," Nat. Commun. 7(May), 11441 (2016).

${ }^{19} \mathrm{P}$. Baggethun, see https://imagej.nih.gov/ij/plugins/radial-profile.html for "Radial profile plot" (2002).

${ }^{20} \mathrm{~A}$. Altaweel, "Synthèse de nanostructures d'oxyde de cuivre par micro-post-décharge micro-ondes à pression atmosphérique," doctoral thesis, Université de Lorraine, 2018.

${ }^{21}$ R. K. Swarnkar, S. C. Singh, and R. Gopal, "Effect of aging on copper nanoparticles synthesized by pulsed laser ablation in water: Structural and optical characterizations," Bull. Mater. Sci. 34(7), 1363-1369 (2011).

${ }^{22}$ I. Cameán et al., "Influence of the inherent metal species on the graphitization of methane-based carbon nanofibers," Carbon 50(15), 5387-5394 (2012).

${ }^{23}$ X. Glad, L. De Poucques, J. A. Jaszczak, M. Belmahi, J. Ghanbaja, and J. Bougdira, "Plasma synthesis of hexagonal-pyramidal graphite hillocks," Carbon 76, 330-340 (2014). 
${ }^{24}$ P. Michel, "Diffraction des électrons: Etudes de strucure," Techniques de l'ingénieur No. P1085 (1990), https://www.techniques-ingenieur.fr/basedocumentaire/archives-th 12 /archives-techniques-d-analyse-tiata/archive-1/ diffraction-des-electrons-p1085/ (in French).

${ }^{25} \mathrm{~L}$. Boufendi and A. Bouchoule, "Particle nucleation and growth in a low-pressure argon-silane discharge," Plasma Sources Sci. Technol. 3(3), 262-267 (1994).

${ }^{26}$ G. Al Makdessi, X. Glad, S. Dap, M. Rojo, R. Clergereaux, and J. Margot, "Influence of a magnetic field on the formation of carbon dust particles in very low-pressure high-density plasmas," J. Phys. D Appl. Phys. 50(15), 155203 (2017).

${ }^{27}$ J. Profili et al., "Interaction of atomized colloid with an A.C. electric field in a dielectric barrier discharge reactor used for deposition of nanocomposite coatings," J. Phys. D Appl. Phys. 50(7), 075201 (2017).

${ }^{\mathbf{2 8}}$ A. Fan, "Copper wafer bonding," Electrochem. Solid State Lett. 2(10), 534 (1999).
${ }^{29}$ A. El Warraky, H. A. El Shayeb, and E. M. Sherif, "Pitting corrosion of copper in chloride solutions," Anti Corros. Methods Mater. 51(1), 52-61 (2004).

${ }^{30}$ T. E. Graedel, K. Nassau, and J. P. Franey, "Copper patinas formed in the atmosphere-I. Introduction,” Corros. Sci. 27(7), 639-657 (1987).

${ }^{31}$ L. Veleva, P. Quintana, R. Ramanauskas, R. Pomes, and L. Maldonado, "Mechanism of copper patina formation in marine environments," Electrochim. Acta 41(10), 1641-1645 (1996).

${ }^{32}$ J. F. Pierson, A. Thobor-Keck, and A. Billard, "Cuprite, paramelaconite and tenorite films deposited by reactive magnetron sputtering," Appl. Surf. Sci. 210(3-4), 359-367 (2003).

${ }^{33}$ S. O. Lumsdon and D. M. Scott, "Assembly of colloidal particles into microwires using an alternating electric field," Langmuir 21(11), 4874-4880 (2005).

${ }^{34}$ T. K. Lowenstein, M. N. Timofeeff, S. T. Brennan, L. A. Hardie, and R. V. Demicco, "Assembly of electrically functional microwires from nanoparticle suspensions via dielectrophoresis," Science 294, 1082-1086 (2001). 